\title{
ANALISIS PERHITUNGAN, PENYETORAN DAN PELAPORAN PAJAK PENGHASILAN (PPh ) PASAL 21 ATAS GAJI PEGAWAI NEGERI SIPIL DI SMA NEGERI 2 PEKALONGAN
}

\author{
Rizka Ariyanti*, Kinanti Restu P. \\ Prodi Akuntansi Politeknik Pusmanu \\ Korespondensi: rizkaariyanti81@gmail.com
}

\begin{abstract}
The purpose of this study was to analyze the calculation, deposit, and reporting of Article 21 Income Tax (PPh) conducted by Pekalongan 2 State High School against the Tax Law No. 36 of 2008. The research method used was descriptive method and data collection techniques by field study and literature. The results of this study indicate that the calculation, deposit and reporting of Article 21 Income Tax on Salaries of Civil Servants (PNS) of Pekalongan 2 State Senior High Schools is in accordance with Law Number 36 of 2008 concerning Income Taxes, and Minister of Finance Regulation Number 101 / PMK. 010/2016 concerning the amount of PTKP (income not taxable), in addition there are findings on the calculation of PPh Article 21 in determining the amount of PTKP an Dra. Setyo Rahayu. Whereas for the Deposit and Reporting of Article $21 \mathrm{PPh}$ it has been running well, disciplined, orderly and on time. If the Article $21 \mathrm{PPh}$ collection carried out by the government wants to increase, then the income / income gained by the employees must also be increased.
\end{abstract}

Keywords: Tax Reporting, Income Tax Article 21, PTKP

\begin{abstract}
ABSTRAK
Tujuan penelitian ini adalah untuk menganalisis perhitungan, penyetoran, dan pelaporan Pajak Penghasilan $(\mathrm{PPh})$ pasal 21 yang dilakukan SMA Negeri 2 Pekalongan terhadap Undang-Undang Perpajakan Nomor 36 Tahun 2008. Metode penelitian yang digunakan yaitu metode deskriptif dan teknik pengumpulan data dengan cara studi lapangan dan kepustakaan.Hasil penelitian ini menunjukkan bahwa perhitungan, penyetoran dan pelaporan PPh Pasal 21 atas Gaji Pegawai Negeri Sipil (PNS) SMA Negeri 2 Pekalongan telah sesuai Undang-undang Nomor 36 Tahun 2008 tentang Pajak Penghasilan, dan Peraturan Menteri Keuangan Nomor 101/PMK.010/2016 tentang Besarnya PTKP (PenghasilanTidak Kena Pajak), selain itu terdapat temuan atas perhitungan PPh Pasal 21 dalam penentuan besarnya PTKP a.n Dra. Setyo Rahayu. Sedangkan untuk Penyetoran dan Pelaporan PPh Pasal 21 nya sudah berjalan dengan baik, disiplin, teratur dan tepat waktu. Apabila pemungutan $\mathrm{PPh}$ Pasal 21 yang dilakukan pemerintah ingin mengalami peningkatan maka harus ditingkatkan pula pendapatan/penghasilan yang diperoleh pegawainya.
\end{abstract}

Kata Kunci : Pelaporan Pajak, Pajak Penghasilan Pasal 21, PTKP

\section{PENDAHULUAN}

Pembangunan nasional sebuah negara membutuhkan berbagai sumber penerimaan yang berasal dari dalam maupun dari luar negeri. Sumber penerimaan dari dalam negeri meliputi penerimaan perpajakan dan Penerimaan Negara Bukan Pajak (PNBP) berupa penerimaan sumber daya alam migas dan non migas, laba Badan Usaha Milik Negara (BUMN) dan PNBP lainnya, sedangkan penerimaan dari luar negeri dapat berupa hibah dari negara lain.

Berdasarkan rincian APBN Tahun 2016 dapat disimpulkan bahwa yang memberikan andil besar dalam membiayai pengeluaran dan pembangunan nasional tersebut yaitu berasal dari sumber pajak. Sedangkan Salah satu pos pajak yang memilikiperanan 
penting bagi pemerintah adalah Pajak Penghasilan $(\mathrm{PPh})$ termasuk Pajak Penghasilan $(\mathrm{PPh})$ Pasal 21.

Pegawai Negeri Sipil (PNS) yang mendapatkanpenghasilan tetap dan teratur setiap bulan berupa gaji dan tunjangan nantinya akan dipotong PPh Pasal 21. Berdasarkan Peraturan Pemerintah Nomor 80 tahun 2010, PPh Pasal 21 baik final maupun tidak final yang telah dipotong dari penghasilan PNS nantinya akan disetor dan dilaporkan oleh bendahara pemerintah ke kas negara. Pelaporan ini dilakukan bendahara dengan menggunakan Surat Pemberitahuan (SPT) yang dikirim ke Kantor Pelayanan Pajak (KPP).

Namun seiring perkembangan perekonomian yang diikuti pula dengan perubahan kebijakan perpajakan. Undang-Undang Pajak yang dijalankan seringkali mengalami perubahan. Diantaranya adalah perubahan mengenai tarif Pasal 17, Penghasilan Tidak Kena Pajak (PTKP), dan pengurang penghasilan bruto seperti biaya jabatan dan iuran pensiun. Hal ini tentunya akan menimbulkan perubahan dalam perhitungan PPh Pasal 21 bagi PNS. Sehingga sangat perludibutuhkan analisis kesesuaian perhitungannya sekaligus menjelaskan tata cara penyetoran juga pelaporan pajak atas PNS oleh SMA Negeri 2 Pekalongan, agar sesuai dengan Undang-Undang tentang Pajak Penghasilan(PPh) yang berlaku saat ini.

\section{RUMUSAN MASALAH}

Rumusan masalah dalam penelitian ini yaitu bagaimana perhitungan, penyetoran dan pelaporan pajak penghasilan pasal 21 atas gaji pegawai negeri ssipil di SMA Negeri 2 Pekalongan

\section{LANDASAN TEORI}

\subsection{Pajak Penghasilan (PPh) Pasal 21}

\subsubsection{Pengertian PPh Pasal 21}

Menurut PMK Nomor 101/PMK.010/2016 Pasal 1 Ayat 2 Pajak Penghasilan Pasal 21 adalah pajak atas penghasilan berupa gaji, upah, honorarium, tunjangan, dan pembayaran lain dengan nama dan dalam bentuk apapun sehubungan dengan pekerjaan atau jabatan, jasa dan kegiatan yang dilakukan oleh orang pribadi Subjek Pajak dalam negeri

\subsubsection{Pemotong PPh Pasal 21}

a) Pemberi kerja yang membayar gaji, upah, honorarium, tunjangan dan pembayaran lain sebagai imbalan sehubungan dengan pekerjaan yang dilakukan oleh pegawai atau bukan pegawai.

b) Bendahara pemerintah yang membayar gaji, upah, honorarium, tunjangan, dan pembayaran lain sehubungan dengan pekerjaan, jasa, atau kegiatan.

c) Dana pensiun atau badan lain yang membayarkan uang pensiun dan pembayaran lain dengan nama apapun dalam rangka pensiun.

d) Badan yang membayar honorarium atau pembayaran lain sebagai imbalan sehubungan dengan jasa termasuk jasa tenaga ahli yang melakukan pekerjaan bebas.

e) Penyelenggara kegiatan yang melakukanpembayaran sehubungan dengan pelaksanaan suatu kegiatan.

\subsubsection{Subjek PPh Pasal 21}

Subjek Pajak Penghasilan pasal 21 adalah penerima penghasilan yang dipotong Pajak Penghasilan pasal 21. 
Menurut UU No.36 Tahun 2008 yang menjadi subjek pajak terdiri dari:

a) Orang pribadi yang bertempat tinggal di Indonesia, orang pribadi yang berada di Indonesia lebih dari 183 (seratus delapan puluh tiga) hari dalam jangka waktu 12 (dua belas) bulan, atau orang pribadi yang dalam suatu tahun pajak berada di Indonesia dan mempunyai niat untuk bertempat tinggal di Indonesia;

b) Badan yang didirikan atau bertempat kedudukan di Indonesia, kecuali unit tertentu dari badan pemerintah yang memenuhi kriteria: 1 . Pembentukannya berdasarkan ketentuan peraturan perundang-undangan; 2. Pembiayaannya bersumber dari Anggaran Pendapatan dan Belanja Negara atau Anggaran Pendapatan dan Belanja Daerah. 3. Penerimaannya dimasukkan dalam anggaran Pemerintah Pusat atau Pemerintah Daerah; dan 4. Pembukuannya diperiksa oleh aparat pengawasan fungsional Negara.

c) Warisan yang belum terbagi sebagai satu kesatuan menggantikan yang berhak.

\subsubsection{Tidak Termasuk Subjek Pajak Penghasilan Pasal 21}

a) Kantor perwakilan negara asing.

b) Pejabat-pejabat perwakilan diplomatik dan konsulat atau pejabat-pejabat lain dari negara asing dan orang-orang yang diperbantukan kepada mereka yang bekerja pada dan bertempat tinggal bersama- sama mereka dengan syarat bukan warga Negara Indonesia dan di Indonesia tidak menerima atau memperoleh penghasilan di luar jabatan atau pekerjaannya tersebut serta negara bersangkutan memberikan perlakuan timbal balik.

c) Organisasi-organisasi internasional dengan syarat:

1) Indonesia menjadi anggota organisasi tersebut

2) Tidak menjalankan usaha atau kegiatan lain untuk memperoleh penghasilan dari Indonesia selain memberikan pinjaman kepada pemerintah yang dananya berasal dari iuran para anggota.

d) Pejabat-pejabat perwakilan organisasi internasional dengan syarat bukan warga negara Indonesia dan tidak menjalankan usaha, kegiatan, atau pekerjaan lain untuk memperoleh penghasilan dari Indonesia.

\subsubsection{Tarif Pajak yang Diterapkan atas Penghasilan Kena Pajak bagi Wajib Pajak Orang Pribadi Dalam Negeri}

Adapun tarif pajak yang diterapkan atas penghasilan kena pajak bagi wajib pajak orang pribadi dalam negeri dapat dilihat pada tabel 2.1 dibawah:

Tabel 1 Tarif Pajak

No.

Lapisan Penghasilan Kena Pajak

Tarif Pajak

\begin{tabular}{rll}
\hline 1 & Sampai dengan Rp. 50.000.000,- & $5 \%$ \\
\hline 2 & Di atas Rp. 50.000.000,- s/d Rp. 250.000.000,- & $15 \%$ \\
\hline 3 & Di atas Rp. 250.000.000,- s/d Rp. 500.000.000,- & $25 \%$ \\
\hline 4 & Di atas Rp. 500.000.000,- & $30 \%$
\end{tabular}

Sumber : Undang-undang RI No.36 Tahun 2006 


\subsubsection{Pengurangan Yang Diperbolehkan}

a) Dasar pengenaan PPh Pasal 21 atas penghasilan tetap dan teratur setiap bulan adalah Penghasilan Kena Pajak.

b) Besarnya Penghasilan neto bagi Pejabat Negara, PNS, Anggota TNI, atau Anggota POLRI ditentukan berdasarkan jumlah seluruh penghasilan tetap dan teratur setiap bulan dikurangi dengan :

1) Biaya jabatan sebagaimana diatur dalam Peraturan Menteri Keuangan yang mengatur tentang biaya jabatan; dan

2) Iuran yang terkait dengan gaji yang dibayar oleh Pejabat Negara, PNS, Anggota TNI, atau Anggota POLRI kepada dana pensiun yang pendiriannya telah disahkan oleh Menteri Keuangan atau badan penyelenggara tunjangan hari tua atau jaminan hari tua yang dipersamakan dengan dana pensiun yang pendiriannya telah disahkan oleh Menteri Keuangan.

c) Besarnya penghasilan neto sebagaimana dimaksud pada ayat(2) bagipensiunanditentukan berdasarkan seluruh penghasilan tetap dan teratur setiap bulan dikurangi dengan biaya pensiun sebagaimana diatur dalam Peraturan Menteri Keuangan yang mengatur tentang biaya pensiun.

d) Besarnya Penghasilan Kena Pajak ditentukan berdasarkan penghasilan neto dikurangi Penghasilan Tidak Kena Pajak.

\subsubsection{NPWP}

Nomor Pokok Wajib Pajak biasa disingkat NPWP adalah nomor yang diberikan kepada wajib pajak (WP) sebagai sarana dalam administrasi perpajakan yang dipergunakan sebagai tanda pengenal diri atau identitas wajib pajak dalam melaksanakan hak dan kewajiban perpajakannya.

\subsubsection{Penghasilan Tidak Kena Pajak (PTKP)}

a) Besarnya PTKP per tahun menurut Peraturan Menteri Keuangan Nomor 101/PMK.010/2016 adalah sebagai berikut:

1) Rp. 54.000.000,00 (lima puluh empat juta rupiah) untuk diri Wajib Pajak orang pribadi;

2) Rp. 4.500.000,00 (empat juta lima ratus ribu rupiah) tambahan untuk Wajib Pajak yang kawin;

3) Rp. 4.500.000,00 (empat juta lima ratus ribu rupiah) tambahan untuk setiap anggota keluarga sedarah dan keluarga semenda dalam garis keturunan lurus serta anak angkat, yang menjadi tanggungan sepenuhnya, paling banyak 3 (tiga) orang untuk setiap keluarga.

b) Besarnya PTKP perbulan menurut Peraturan Menteri Keuangan Nomor 101/PMK.010/2016 adalah sebagai berikut:

1) Rp. 4.500.000,00 (empat juta lima ratus ribu rupiah) untuk diri Wajib Pajak orang pribadi;

2) Rp. 375.000,00 (tiga ratus tujuh puluh lima ribu rupiah) tambahan untuk Wajib Pajak yang kawin;

3) Rp. 375.000,00 (tiga ratus tujuh puluh lima ribu rupiah) tambahan untuk setiap anggota keluarga sedarah dan keluarga semenda dalam 


\subsubsection{Tata Cara Penghitungan PPh Pasal 21}

garis keturunan lurus serta anak angkat, yang menjadi tanggungan sepenuhnya, paling banyak 3 (tiga) orang untuk setiap keluarga.

Cara menghitung PPh Pasal 21 untuk penghasilan tetap dan teratur setiap bulan dibedakan menjadi 2 (dua), antara lain:

a) Penghitungan masa atau bulanan yang menjadi dasar pemotongan $\mathrm{PPh}$ Pasal 21 yang terutang untuk setiap masa pajak, yang dilaporkan dalam SPT masa PPh Pasal 21, selain masa pajak Desember atau masa pajak terakhir,

b) Penghitungan kembali sebagai dasar pengisian 1721 A2 dan pemotongan PPh Pasal 21 yang terutang untuk masa pajak Desember atau masa pajak terakhir.

Penghitungan pada masa pajak Desember dilakukan bagi Pejabat Negara, PNS, Anggota TNI, POLRI yang bekerja sampai akhir tahun takwim dan bagi pensiunan yang menerima penghasilan pensiun sampai akhir tahun takwim.

Penghitungan masa atau bulanan selain masa pajak Desember atau masa pajak penghitungan PPh Pasal 21 bagi Pejabat Negara, PNS, Anggota TNI dan Anggota POLRI meliputi :

a) Untuk menghitung $\mathrm{PPh}$ Pasal 21 atas penghasilan tetap dan teratur setiap bulan terlebih dahulu dihitung seluruh penghasilan bruto yang diterima selama sebulan yang meliputi seluruh gaji dan tunjangan.

b) Selanjutnya dihitung jumlah penghasilan netto sebulan yang diperoleh dengan cara mengurangi penghasilan bruto sebulan dengan biaya jabatan dan iuran pensiun,

c) Selanjutnya dihitung penghasilan netto setahun yaitu jumlah penghasilan netto sebulan dikalikan 12 bulan,

d) Dalam hal Pejabat Negara, PNS, Anggota TNI, atau anggota POLRI mulai bekerja setelah bulan Januari, maka penghasilan netto setahun dihitung dengan mengalikanpenghasilan netto sebulandenganbanyaknya bulan sejak Pejabat Negara, PNS, Anggota TNI, maupun Anggota POLRI mulai bekerja sampai dengan bulan Desember,

e) Selanjutnya dihitung Penghasilan Kena Pajak yaitu sebesar penghasilan netto setahun sebagaimana dimasksud pada angka(3)atau(4)dikurangi dengan PTKP, Penghasilan PPh Pasal 21 terutang atas perkiraan penghasilan setahun dihitung dengan menerapkan tarif pasal $17 \mathrm{UU} \mathrm{PPh}$ terhadap PKP,

f) Selanjutnya dihitung $\mathrm{PPh}$ Pasal 21 yang ditanggung oleh Pemerintah sebulan, yaitu:

1) Jumlah $\mathrm{PPh}$ Pasal 21 terutang atas penghasilan sebagaimana angka (3) dibagi dengan 12,

2) Jumlah $\mathrm{PPh}$ Pasal 21 terutang atas penghasilan sebagaimana dimaksud pada angka (4)dibagibanyaknya bulanyangmenjadi faktorpengali sebagaimana dimaksud pada angka (4). 


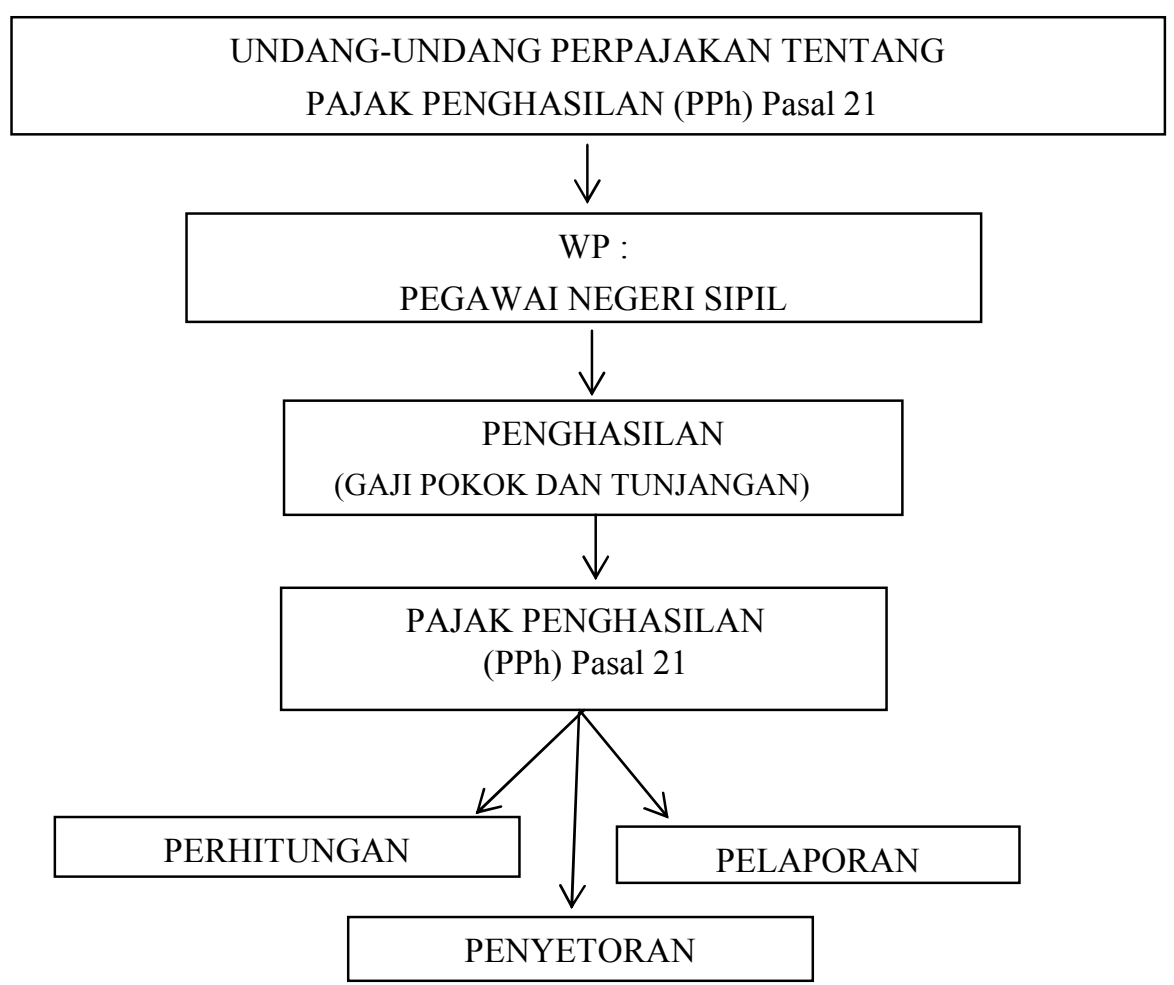

Gambar 1 Kerangka Pemikiran Penelitian

\section{METODE PENELITIAN}

Metode analisis data yang digunakan dalam penelitian ini adalah metode deskriptif analisis, menurut Sugiyono (2010:147) menyebutkan bahwametode deskriptif analisis merupakan metode penelitian yang menggambarkan permasalahan atau kasus yang dikemukakan berdasarkan fakta yang ada dengan fakta yang bersifat khusus, kemudian diteliti dan dipecahkan permasalahannya dan ditarik kesimpulan secara umum.

Prosedur analisis dimulai dengan pengambilan data dan informasi mengenai sejarah sekolah,struktur organisasi beserta tugas dan tanggung jawab pegawai dan jumlah pegawai berdasarkan pangkat dan golongan yang telah diolah. Menganalisis daftar gaji yang kemudian menganalisis kesesuaian mengenai perhitungan,pemyetoran dan pelaporan $\mathrm{PPh}$ Pasal 21 yang dilakukan SMA Negeri 2 Pekalongan dengan ketentuan Undang-undang Perpajakan tentang Pajak Penghasilan yang berlaku saat ini dan kemudian akan ditarik kesimpulan mengenai analisis perhitungan,penyetoran,dan pelaporan PajakPenghasilan $(\mathrm{PPh})$ Pasal 21 atas Gaji Pegawai Negeri Sipil di SMA Negeri 2 Pekalongan.

\section{PEMBAHASAN}

\subsection{Analisis Perhitungan PPh Pasal 21}

Informasi mengenai perhitungan PPh Pasal 21 atas gaji Pegawai Negeri Sipil yang dilakukan oleh SMA Negeri 2 Pekalongan tidak tertera, namun dalam daftar gaji dicantumkan besarnya nominal pajak terutangnya/ potongan $\mathrm{PPh}$.

Contoh Perhitungan PPh Pasal 21 atas anam Lalan Prihadi GolonganII/c, (TK 1000) dapat dilihat pada Tabel 2 berikut ini. 
Tabel 2 Perhitungan PPh Pasal 21 an. Lalan Prihadi Golongan II/c (TK 1000)

\begin{tabular}{|c|c|c|c|c|}
\hline Gaji Pokok & $\mathrm{Rp}$. & $2,809,500$ & & \\
\hline Tunjangan Istri/Suami & $\mathrm{Rp}$. & - & & \\
\hline Tunjangan Anak & $\mathrm{Rp}$. & - & & \\
\hline Jumlah Gaji dan Tunj. Keluarga & & & Rp. & $2,809,500$ \\
\hline Tunjangan Umum & $\mathrm{Rp}$. & 180,000 & & \\
\hline Tambahan Tunjangan Umum & $\mathrm{Rp}$. & - & & \\
\hline Tunjangan Struktural & $\mathrm{Rp}$. & - & & \\
\hline Tunjangan Fungsional & $\mathrm{Rp}$. & - & & \\
\hline Tunjangan Beras & $\mathrm{Rp}$. & 72,420 & & \\
\hline Tunjangan PPh & $\mathrm{Rp}$. & - & & \\
\hline \multirow[t]{2}{*}{ Pembulatan } & $\mathrm{Rp}$. & 30 & & \\
\hline & & & Rp. & 252,450 \\
\hline Penghasilan Bruto & & & Rp. & $3,061,950$ \\
\hline \multicolumn{5}{|l|}{ Pengurangan: } \\
\hline IWP $10 \%$ & $\mathrm{Rp}$. & 280,950 & & \\
\hline Lain-lain & Rp. & 5,000 & & \\
\hline \multirow[t]{2}{*}{ Potongan PPh } & Rp. & - & & \\
\hline & & & Rp. & 285,950 \\
\hline Penghasilan Netto Sebulan & & & Rp. & $2,776,000$ \\
\hline penghasilan Netto Setahun x12bulan & & & Rp. & $33,312,000$ \\
\hline \multicolumn{5}{|l|}{ PTKP : } \\
\hline Untuk WP sendiri & $\mathrm{Rp}$. & $54,000,000$ & & \\
\hline Tambahan WP kawin & $\mathrm{Rp}$. & - & & \\
\hline Tambahan anak & $\mathrm{Rp}$. & - & & \\
\hline Total Penghasilan Tidak Kena Pajak (PTKP) & & & Rp. & $54,000,000$ \\
\hline Penghasilan Kena Pajak (PKP) & & & & - \\
\hline \multicolumn{5}{|l|}{ PPh Pasal 21 terutang / tahun : } \\
\hline $5 \% \times$ PKP & & & & - \\
\hline PPh Pasal 21 terutang / bulan : & & & & - \\
\hline
\end{tabular}

Sumber : Data Primer diolah Tahun 2017

Berdasarkan penghitungan PPh Pasal 21 atas Lalan Prihadi PNS Golongan II/c TK 1000 dapat dihitung sebagai berikut :

a) Menghitung Penghasilan Bruto

Penghasilan Bruto dihitung dengan menjumlahkan besarnya gaji dengan tunjangan-tunjangan yang berkaitan dengan gaji. Yang pertama dapat dijumlahkan terlebih dahulu antara gaji sebesar $\mathrm{Rp}$ 2,809,500 dengan tunjangan keluarga berupa tunjangan istri dan tunjangan anak. Namun dalam hal ini Lalan Prihadi tidak menerima tunjangan keluarga baik tunjangan istri maupun tunjangan anak sehingga untuk besarnya penghasilan bruto hanya berdasarkan gaji pokoknya saja.

Selain itu adapun beberapa tunjangan lain yang dapat menambah penghasilan bruto seperti tunjangan umum dan tunjangan beras. Dimana tunjangan umum untuk golongan II ini ditentukan sebesar Rp 180,000dan untuk besarnya tunjangan beras atas Lalan Prihadi sebesar Rp 72.420 karena tidak ada jumlah anggota keluarga lain serta terdapat penambahan pembulatan sebesar Rp 30 Sehingga dapat diperoleh penghasilan bruto sebesar Rp. 3,061,950.

b) Menghitung Penghasilan Netto

Penghasilan Netto sebulan dapat diperoleh berdasarkan penghasilan bruto dikurangi dengan faktor pengurangannya yaitu sebesar $\mathrm{Rp}$ 2,776,000, faktor pengurangannya tersebut meliputi IWP (10\% dari jumlah gaji dan tunjangan keluarga) sebesar Rp 280,950 dan potongan lain berupa iuran bapertarum untuk 
golongan II sebesar Rp 5000. Setelah itu dihitung penghasilan netto selama setahun dikalikan dengan 12 bulan menjadi Rp33,312,000.

c) Menentukan besarnya PTKP (Penghasilan Tidak Kena Pajak)

Setelah menghitung Penghasilan netto selama setahun, langkah selanjutnya yaitu menentukan besaran PTKP atas tanggungan yang dimiliki. Namun Lalan Prihadi tidak memiliki tanggungan, hal tersebut dimaksudkan dengan kode TK 1000 yang artinya bahwa Lalan Prihadi merupakan Wajib Pajak (WP) yang sudah menikah, beristri dan memiliki anak namun tanggungan istri dan anak nya masuk dalam tanggungan gaji istri sebagai PNS yang menerima gaji lebih besar dari suami. Sehingga besaran PTKP atas Lalan Prihadi sebesar Rp 54,000,000 hanya untuk WP sendiri.

d) Menghitung besarnya PKP (Penghasilan Kena Pajak)

Setelah ditentukan besarnya PTKP sejumlah Rp 54,000,000 maka dapat diketahui jumlah PKP selama sebulan dengan cara penghasilan netto setahun dikurangi dengan besarnya PTKP.

Dalam hal ini PTKP Lalan Prihadi sebagai wajib pajak lebih besar dibandingan dengan jumlah penghasilan netto setahun, maka Lalan Prihadi bersifat nihil atau tidak dikenakan potongan PPh Pasal 21 atas gaji.

Contoh perhitungan $\mathrm{PPh}$ Pasal 21 atas nama Dra. Sri Setyo Rahayu GolonganIV/a, (K 1101) dapat dilihat pada Tabel 3 berikut ini.

Tabel 3 Perhitungan PPh Pasal 21 atas nama Dra. Sri Setyo Rahayu Golongan IV/a (K 1101)

\begin{tabular}{|c|c|c|c|c|}
\hline Gaji Pokok & $\mathrm{Rp}$. & $4,762,000$ & & \\
\hline Tunjangan Istri/Suami & Rp. & 476,200 & & \\
\hline Tunjangan Anak & $\mathrm{Rp}$. & 95,240 & & \\
\hline Jumlah Gaji dan Tunj. Keluarga & & & Rp. & $5,333,440$ \\
\hline Tunjangan Umum & Rp. & - & & \\
\hline Tambahan Tunjangan Umum & $\mathrm{Rp}$. & - & & \\
\hline Tunjangan Struktural & $\mathrm{Rp}$. & - & & \\
\hline Tunjangan Fungsional & Rp. & 389,000 & & \\
\hline Tunjangan Beras & $\mathrm{Rp}$. & 217,260 & & \\
\hline Tunjangan $\mathrm{PPh}$ & Rp. & 44,470 & & \\
\hline \multirow[t]{2}{*}{ Pembulatan } & Rp. & 44 & & \\
\hline & & & Rp. & 650,774 \\
\hline Penghasilan Bruto & & & Rp. & $5,984,214$ \\
\hline \multicolumn{5}{|l|}{ Pengurangan : } \\
\hline IWP $10 \%$ & $\mathrm{Rp}$. & 533,344 & & \\
\hline Lain-lain & $\mathrm{Rp}$. & 10,000 & & \\
\hline \multirow[t]{2}{*}{ Potongan PPh } & $\mathrm{Rp}$. & 44,470 & & \\
\hline & & & Rp. & $\mathbf{5 8 7 , 8 1 4}$ \\
\hline Penghasilan Netto Sebulan & & & Rp. & $5,396,400$ \\
\hline penghasilan Netto Setahun x12bulan & & & Rp. & $64,756,800$ \\
\hline \multicolumn{5}{|l|}{ PTKP : } \\
\hline Untuk WP sendiri & $\mathrm{Rp}$. & $54,000,000$ & & \\
\hline Tambahan WP kawin & Rp. & $4,500,000$ & & \\
\hline Tambahan anak & Rp. & $4.500,000$ & & \\
\hline Total Penghasilan Tidak Kena Pajak (PTKP) & & & Rp. & $63,000,000$ \\
\hline Penghasilan Kena Pajak (PKP) & & & Rp. & $1,756,800$ \\
\hline \multicolumn{5}{|l|}{ PPh Pasal 21 terutang / tahun : } \\
\hline $5 \% \times$ PKP & & & Rp. & 87,840 \\
\hline PPh Pasal 21 terutang / bulan : & & & Rp. & 7,320 \\
\hline
\end{tabular}

Sumber : Data Primer diolah Tahun 2017 
Berdasarkan penghitungan PPh Pasal 21 atas Dra. Sri Setyo Rahayu, PNS Golongan IV/a K 1101 dapat dihitung sebagai berikut :

a) Menghitung Penghasilan Bruto

Penghasilan Bruto dihitung dengan menjumlahkan besarnya gaji dengan tunjangan-tunjangan yang berkaitan dengan gaji. Yang pertama dapat dijumlahkan terlebih dahulu antara gaji yang diperoleh sebesar Rp 4,762,000 dengan tunjangan keluarga berupa tunjangan suami dan tunjangan anak. Tunjangan suami dihitung 10\% dari gaji yaitu sebesar Rp 476,200 dan tunjangan anak dihitung 2\% dari gaji pokok yaitu sebesar Rp 95,240, sehingga dapat dihitung jumlah gaji dan tunjangan keluarga sebesar Rp. 5,333,440.

Selain itu adapun beberapa tunjangan lain yang dapat menambah penghasilan bruto seperti tunjangan fungsional, tunjangan beras dan tunjangan $\mathrm{PPh}$. Dimana tunjangan fungsional untuk golongan IV ini ditentukan sebesar Rp 389,000, sedangkan untuk tunjangan beras dikenakan per orang sebesar Rp 72.420 karena jumlah keluarganya 3 orang makadikalikan 3 menjadi Rp217,260 serta tunjangan PPh sebesar Rp 44,470 serta terdapat penambahan pembulatan sebesar Rp 44 Sehingga dapat diperoleh penghasilan bruto sebesar Rp. 5,984,214.

b) Menghitung Penghasilan Netto

Penghasilan Netto sebulan dapat diperoleh dari penghasilan bruto dikurangi dengan faktor pengurangannya yaitu sebesar Rp. 5,396,400; faktor pengurangannya tersebut meliputi IWP $(10 \%$ dari jumlah gaji dan tunjangan keluarga) sebesar Rp 533,344; potongan lain berupa iuran bapertarum untuk golongan IV sebesar Rp 10,000 dan potongan PPh sebesar Rp 44,470 kemudian dihitung penghasilan netto selama setahun dikalikan dengan 12 bulan menjadi Rp. $64,756,800$.

c) Menentukan besarnya PTKP (Penghasilan Tidak Kena Pajak)

Setelah menghitung Penghasilan netto selama setahun, langkah selanjutnya yaitu menentukan besaran PTKP atas tanggungan yang dimiliki. Adapun tanggungan Dra. Sri Setyo Rahayu. kode K 1101, hal tersebut dimaksudkan bahwa Dra. Sri Setyo Rahayu. merupakan Wajib Pajak (WP) yang sudah menikah, bersuami dan memiliki tanggungan 1 anak. Sehingga besaran PTKP atas Dra. Sri Setyo Rahayusebesar Rp 54,000,000 untuk WP sendiri dan Rp. 4,500,000 untuk tambahan WP kawin, dan Rp. 4,500,000 untuk tanggungan anak, sehingga jika dijumlahkan maka jumlah PTKP Dra. Sri Setyo Rahayusebesar Rp. $63,000,000$.

d) Menghitung besarnya PKP (Penghasilan Kena Pajak)

Setelah ditentukan besarnya PTKP sejumlah Rp. 63,000,000 maka dapat diketahui jumlah PKP selama sebulan dengan cara penghasilan netto setahun dikurangi dengan besarnya PTKP yaitu Rp. 1,756,800.

Setelah diketahui PKP nya maka dapat dihitung PPh Pasal 21 Terutangnya.

e) Menghitung PPh Pasal 21 Terutang

Cara menghitung PPh Pasal 21 terutang/tahun nya yaitu dengan cara mengalikan tarif pajak terhadap PKP bagi Wajib Pajak. Adapun tarif pajak untuk Dra. Sri Setyo Rahayu adalah 5\% karena besarnya PKP termasuk dalam penghasilan Rp 0 - Rp 50,000,000; sehingga dapat diperoleh besarnya PPh Pasal $21 /$ tahun nya yaitu $5 \%$ dari $\mathrm{Rp} \quad 1,756,800=\mathrm{Rp} \quad 87,840$, yang kemudian dibagi 
12 untuk memperoleh PPh Pasal 21/ bulannya yang akan dipotong per bulannya yaitu sebesar $\operatorname{Rp} 7,320$.

Setelah dilakukan analisa perhitungan PPh Pasal 21 atas Dra. Sri Setyo Rahayu terjadi selisih dalam perhitungan sebesar Rp 37,150 dari Rp 44, 470 menjadi Rp 7,320 untuk potongan PPh Pasal 21 yang terdapat dalam daftar gaji. Hal ini dikarenakan terdapat kesalahan pada kode tanggungan PKTP nyadimana dalam daftar gaji tertera K 1101 padahal dalam perhitungannya jika menggunakan kode tersebut dihasilkan $\mathrm{Rp}$ 7,320 sedangkan didalam daftar gaji didapatkan Rp 44,470 seharusnya jika dihasilkan Rp 44,470 masuk dalam K 1000 tanpa ada tanggungan suami ataupun anak.

Contoh Perhitungan PPh Pasal 21 atas nama Budi Hartati, M.Pd Golongan IV/b, (TK 1000) dapat dilihat pada Tabel 4 berikut ini.

Tabel 4 Perhitungan PPh Pasal 21 atas Budi Hartati, M.Pd Golongan IV/b (TK 1000)

\begin{tabular}{|c|c|c|c|c|}
\hline Gaji Pokok & $\mathrm{Rp}$. & $4,665,000$ & & \\
\hline Tunjangan Istri/Suami & $\mathrm{Rp}$. & - & & \\
\hline Tunjangan Anak & $\mathrm{Rp}$. & - & & \\
\hline Jumlah Gaji dan Tunj. Keluarga & & & Rp. & $4,665,000$ \\
\hline Tunjangan Umum & $\mathrm{Rp}$. & - & & \\
\hline Tambahan Tunjangan Umum & $\mathrm{Rp}$. & - & & \\
\hline Tunjangan Struktural & $\mathrm{Rp}$. & - & & \\
\hline Tunjangan Fungsional & $\mathrm{Rp}$. & 640,000 & & \\
\hline Tunjangan Beras & $\mathrm{Rp}$. & 72,420 & & \\
\hline Tunjangan PPh & $\mathrm{Rp}$. & 19,350 & & \\
\hline Pembulatan & $\mathrm{Rp}$. & 80 & & \\
\hline & & & Rp. & $\mathbf{7 3 1 , 8 5 0}$ \\
\hline Penghasilan Bruto & & & Rp. & $5,396,850$ \\
\hline Pengurangan: & & & & \\
\hline IWP $10 \%$ & $\mathrm{Rp}$. & 466,500 & & \\
\hline Lain-lain & $\mathrm{Rp}$ & 10,000 & & \\
\hline Potongan PPh & $\mathrm{Rp}$ & 19,350 & & \\
\hline & & & Rp. & 495,850 \\
\hline Penghasilan Netto Sebulan & & & Rp. & $4,901,000$ \\
\hline penghasilan Netto Setahun x12bulan & & & Rp. & $58,812,000$ \\
\hline \multicolumn{5}{|l|}{ PTKP : } \\
\hline Untuk WP sendiri & $\mathrm{Rp}$ & $54,000,000$ & & \\
\hline Tambahan WP kawin & $\mathrm{Rp}$ & - & & \\
\hline Tambahan anak & $\mathrm{Rp}$ & - & & \\
\hline Total Penghasilan Tidak Kena Pajak (PTKP) & & & Rp. & $54,000,000$ \\
\hline Penghasilan Kena Pajak (PKP) & & & Rp. & $4,812,000$ \\
\hline \multicolumn{5}{|l|}{ PPh Pasal 21 terutang / tahun : } \\
\hline $5 \% \times$ PKP & & & Rp. & 240,600 \\
\hline PPh Pasal 21 terutang / bulan : & & & Rp. & 20,050 \\
\hline
\end{tabular}

Sumber : Data Primer diolah Tahun 2017

Berdasarkan perhitungan PPh Pasal 21 atas Budi Hartati, M.Pd PNS Golongan IV/b (TK 1000) dapat dihitung sebagai berikut :

a) Menghitung Penghasilan Bruto

Penghasilan Bruto dihitung dengan menjumlahkan besarnya gaji dengan tunjangan-tunjangan yang berkaitan dengan gaji. Yang pertama dapat dijumlahkan terlebih dahulu antara gaji yang diperoleh sebesar Rp4,665,000 dengan tunjangan keluarga berupa tunjangan suami dan tunjangan anak. Namun dalam hal ini Budi Hartati, M.Pd. tidak menerima tunjangan keluarga baik tunjangan suami maupun tunjangan anak. Sehingga untuk besarnya penghasilan bruto hanya berdasarkan gaji pokoknya saja. 
Selain itu adapun beberapa tunjangan lain yang dapat menambah penghasilan bruto seperti tunjangan fungsional, tunjangan beras dan tunjangan $\mathrm{PPh}$. Dimana tunjangan fungsional untuk golongan IV (kepala sekolah) ini ditentukan sebesar Rp.640,000,. Untuk tunjangan beras atas Budi Hartati, M.Pd. sebesar Rp.72.420 karena tidak ada jumlah anggota keluarga lain serta tunjangan PPh sebesar Rp.19,350 dan terdapat penambahan pembulatan sebesar Rp 80 sehingga dapat diperoleh penghasilan bruto sebesar Rp.5,396,850.

b) Menghitung Penghasilan Netto

Penghasilan Netto sebulan dapat diperoleh dari penghasilan bruto dikurangi dengan faktor pengurangnya yaitu sebesar Rp.4,901,000, faktor pengurangnya tersebut meliputi IWP (10\% dari jumlah gaji dan tunjangan keluarga) sebesar Rp466,500 dan potongan lain berupa iuran bapertarum untuk golongan IV sebesar Rp 10,000 dan potongan PPh sebesar Rp 19.350. Setelah itu dihitung penghasilan netto selama setahun dikalikan dengan 12 bulan menjadi Rp. $58,812,000$.

c) Menentukan besarnya PTKP (Penghasilan Tidak Kena Pajak)

Setelah menghitung Penghasilan netto selama setahun, langkah selanjutnya yaitu menentukan besaran PTKP atas tanggungan yang dimiliki. Namun Budi Hartati, M.Pd tidak memiliki tanggungan, hal tersebut dimaksudkan dengan kode TK 1000 yang artinya bahwa Budi Hartati, M.Pd merupakan Wajib Pajak (WP) yang sudah menikah, bersuami dan memiliki anak namun suami dan anak nya tidak masuk dalam tanggungan sehingga besaran PTKP atas Budi Hartati, M.Pd sebesar Rp 54,000,000 hanya untuk WP sendiri.

d) Menghitung besarnya PKP (Penghasilan Kena Pajak)

Setelah ditentukan besarnya PTKP sejumlah Rp.54,000,000 maka dapat diketahui jumlah PKP dalam satu bulan dengan cara penghasilan netto setahun dikurangi dengan besarnya PTKP yaitu sebesar Rp.4,812,000.

Setelah diketahui PKP nya maka dapat dihitung PPh Pasal 21 Terutangnya.

f) Menghitung PPh Pasal 21 Terutang

Cara menghitung PPh Pasal 21 terutang/tahun nya yaitu dengan cara mengalikan tarif pajak terhadap PKP bagi Wajib Pajak. Adapun tarif pajak untuk Budi Hartati, M.Pd adalah 5\% karena besarnya PKP termasuk dalam penghasilan Rp 0 - Rp 50,000,000; sehingga dapat diperoleh besarnya PPh Pasal 21/tahun nya yaitu 5\% dari Rp. 4,812,000 = Rp. 240,600, yang kemudian dibagi 12 untuk memperoleh PPh Pasal 21/ bulannya yang akan dipotong per bulannya sebesar Rp. Rp 20,050.

Setelah dilakukan analisa perhitungan PPh Pasal 21 atas Budi Hartati, M.Pd. terjadi selisih dalam perhitungan sebesar Rp 700 untuk potongan $\mathrm{PPh}$ Pasal 21 yang terdapat dalam daftar gaji.

Apabila terjadi kurang/lebih bayar tersebut maka berdasarkan Peraturan Menteri Keuangan Nomor 101/PMK.010/2016 Pasal 22 (7) disebutkan bahwa kekurangan penyetoran tersebut dapat diperhitungkan dengan $\mathrm{PPh}$ Pasal 21 yang terutang pada bulan berikutnya melalui SPT Masa PPh Pasal 21 dan dilakukan restitusi apabila terjadi lebih bayar. 


\subsection{Penyetoran PPh Pasal 21}

Mekanisme penyetoran PPh Pasal 21 SMA Negeri 2 Pekalongan adalah sebagai berikut:

a) SMA Negeri 2 Pekalongan mendaftarkan diri sebagai pemotong pajak ke Kantor Pelayanan Pajak Pratama Kota Pekalongan.

b) Penyetoran Pajak Penghasilan Pasal 21 dilakukan dengan menggunakan Surat Setoran Pajak (SSP) yang diisi sesuai perhitungan yang telah dilakukan pemotong pajak. Surat Setoran Pajak (SSP) dibuat dalam rangkap 5 (lima) yang didistribusikan sebagai berikut:

1) Lembar pertama untuk arsip Wajib Pajak;

2) Lembar kedua untuk Kantor Pelayanan Pajak (KPP) Pratama Kota Pekalongan melalui KantorPelayanan Perbendaharaan Negara (KPPN);

3) Lembar ketiga untuk dilaporkan oleh Wajib Pajak ke KantorPelayanan Pajak (KPP) Pratama Kota Pekalongan;

4) Lembar keempat untuk Kantor Penerimaan Pembayaran;

5) Lembar kelima untuk Wajib Pungut atau pihak lain.

c) Pemotong pajak memberikan Bukti pemotongan Pajak Penghasilan Pasal 21 kepada pegawai.

d) Setelah disetor, SSP di-scan dan diarsipkan oleh JuruBayar (Bendahara Sekolah).

e) Penyetoran PPh Pasal 21 dilakukan sebelum tanggal 10 (sepuluh) setiapbulannya oleh bendahara pemerintah.

\subsection{Pelaporan PPh Pasal 21}

SMA Negeri 2 Pekalongan sebagai pemotong pajak wajib melakukan pelaporan Pajak masa tahunan, dalam hal ini Pelaporan pajak menggunakan SPT Masa PPh pasal 21 yang diolah dengan sistem terkomputerisasi.

Adapun mekanisme pelaporan PPh Pasal 21 adalah, sebagai berikut:

a) Pemotong menerima format SPT tahunan berupa entry data Pegawai Negeri Sipil Kota Pekalongan dan Bukti Potong yang kemudian di cetak dan input kedalam alamat web efilling.pajak.go.id/

b) Setelah itu pemotong pajak menggunakan Surat Pemberitahuan tahunan Pajak Penghasilan Pasal 21 beserta lampirannya, Surat Setoran Pajak, dan perhitungan Pajak Penghasilan Pasal 21 yang tertutang ke Kantor Pelayanan Pajak Pratama Kota Pekalongan.

c) Setelah dilaporkan, SPT diarsipkan oleh Juru Bayar (Bendahara Sekolah).

d) SPT Masa PPh Pasal 21 dilaporkan paling lama 3 (tiga) bulan setelah akhir Tahun Pajakke Kantor Pelayanan Pajak (KPP) Pratama Pekalongan.

\section{DAFTAR PUSTAKA}

https://id.wikipedia.org/wiki/Nomor_pokok_wajib_pajak http://library.binus.ac.id/eColls/eThesisdoc/Bab2HTML/2012200736AKBab2004/body.html Kesek, Meilany, dkk. Prosedur Perhitungan dan Pelaporan Pajak Penghasilan (PPh) Pasal 21 Atas Gaji Pegawai pada Pemerintah Kota Bitung.

Mardiasmo, 2011. Perpajakan Edisi Revisi. Yogyakarta: Andi Yogyakarta.

Muljono. 2010. Hukum Pajak-Konsep, Aplikasi dan Penentuan Praktis. Yogyakarta: Andi, Yogyakarta. 
Noeng Muhadjir,1996. Metodologi Penelitian Kualitatif. Yogyakarta: Rakesarasin.

Pratiwi ,Vicky Yuliandhani, dkk. 2016. Analisis Perhitungan, Pemotongan dan Pelaporan Pph Pasal 21 atas PNS TNI AD Pomdam V/Brawijaya Surabaya: Universitas Brawijaya Malang.

Peraturan Menteri Keuangan Nomor 262/PMK.03/2010 Tahun 2010 tentang "Tata Cara Pemotongan Pajak Penghasilan Pasal 21 Bagi Pejabat Negara, PNS, Anggota TNI, Anggota Polri, dan Pensiunannya atas Penghasilan yang Menjadi Beban Anggaran Pendapatan Dan Belanja Negara Atau Anggaran Pendapatan dan Belanja Daerah”.

Peraturan Direktur Jenderal Pajak Nomor PER-16/PJ/2016 Tahun 2016 tentang Pedoman Teknis Tata Cara Pemotongan, Penyetoran dan Pelaporan Pajak Penghasilan Pasal 21 dan/atau Pajak Penghasilan Pasal 26 sehubungan dengan Pekerjaan, Jasa dan Kegiatan Orang Pribadi

Prof. Dr. MJH. Smeeths dalam buku "De Economische Betekenis belastingen" (terjemahan)

Prof. Dr. Rochmat Soemitro, SH.2007. Dasar-dasar hukum pajak dan pajak pendapatan. Bandung; Eresco.

Pudyatmoko, 2007, Penerapan Perhitungan PPh Pasal 21 dengan UU Perpajakan No. 36 Tahun 2008 Pada PT. Global Borneo Mandiri Banjarmasin, Skripsi (Tidak Dipublikasikan), Universitas Lambung Mangkurat Banjarmasin

R. Runtuwarow dan I. Elim., V.Z. Tirayoh, Analisis Penerapan Akuntansi, Vol.4No.1Maret2016,Hal.283-294.

Shaleh, Rahmad, Analisis Perhitungan Pph Pasal 21 Terhadap Gaji Pegawai Tetap pada Puskesmas Sambutan Kecamatan Samarinda Ilir.

Suandy, Erly. 2011. Hukum Pajak, Edisi 5, Jakarta: Salemba Empat.

Sugiyono. 2009. Metode Penelitian Kuantitatif dan Kualitatif. Bandung: CV. Alfabeta

Sugiyono. 2010. Metode Penelitian Administratif. Bandung: Alfabeta.

Sugiyono. 2012. Metode Penelitian Pendidikan.Bandung: CV Alfabeta.

Sugiyono. 2013. Metode Penelitian Pendidikan Pendekatan Kuantitatif, Kualitatif, dan R\&D. Bandung: Alfabeta.

Tamjiddin, Analisis Pengenaan Pajak Penghasilan Pasal 21 Atas Gaji Pegawai Negeri Sipil

Pada Dinas Kebudayaan, Pariwisata, Pemuda Olahraga Kota Banjarbaru: Banjarbaru.

Umi Narimawati. 2008. Metodologi Penelitian Kualitatif dan Kuantitatif, Teori danAplikasi. Bandung: Agung Media

UU Nomor 12 Tahun 2008 Tentang Tunjangan Umum Bagi Pegawai Negeri Sipil.

UU Nomor 36 Tahun 2008 Tentang Pajak Penghasilan.

UU Nomor 80 Tahun 2010 Tentang Tarif Pemotongan dan Pengenaan Pajak Penghasilan Pasal 21 atas Penghasilan yang Menjadi Beban Anggaran Pendapatan dan Belanja Negara atau Anggaran Pendapatan dan Belanja Daerah. 